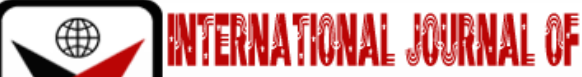

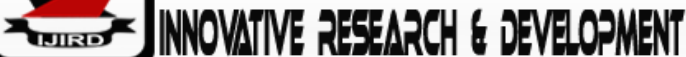

ISSN 2278 - 0211 (Online)

\section{Knowledge and Practice Related to Home Management and Prevention of Coronary Artery Disease, among Wives of the Patients with Coronary Artery Disease}

\begin{tabular}{c} 
Jaseela Ada Kunnimmal \\
Charge Nurse, Cambridge University Hospitals, United Kingdom \\
Sumangala T.J. \\
Retired Professor, Government Nursing College, Kozhikode, India \\
Dr. Roy R Chandran \\
Associate Professor, Department of Physical Medicine and Rehabilitation, \\
Government Medical College, India \\
\hline
\end{tabular}

\begin{abstract}
:
The study was aimed to assess knowledge and practice related to prevention and home management of coronary artery disease (CAD), among wives of the patients with coronary artery disease. The objectives of the study were to assess the knowledge and practice regarding prevention and home management of coronary artery disease among wives of patients with coronary artery disease. A non-experimental survey design was used. A Structured interview schedule was used to assess knowledge and practice related to prevention and home management of coronary artery disease. 116 participants were selected by judgmental sampling from Medical and Cardiology wards of Govt. Medical College Hospital, Kozhikode. The study findings revealed that nearly half (49.1) of the participants had poor knowledge and only (5.2\%) had good knowledge related to prevention and home management of coronary artery disease. Results revealed that41.4\%of participants had poor practice and 58.6\% wives had only average practice and none had good practice to prevent and manage CAD in the family.Of the participants, 56\% had poorhad poor knowledge about the general aspects of CAD. 35.4\% had poor knowledge and $47.4 \%$ had average knowledge and 17.2\%on dietary aspects, Majority (93.1\%) had poor knowledge on exercise to prevent and mange CAD. 96.6\% had poor knowledge and none had good knowledge about sexual life after CAD. 37.1\% had poor practices and more than half of the participants (61.2\%) had average dietary practice in the family and only $1.7 \%$ had good practices of following a heart healthy diet. Majority (85.3\%) of them had poor practice of exercise and none (0\%) had good practice of exercise. Study finding revealed that (44\%) had economic constraints as a stress factor in the family. More than half of them (51.7\%) had poor practice in timely management of pain. The study results project the extent of lack of knowledge and practice of home management in the wives of patients with coronary artery disease. The study findings reveal the contribution of uncontrolled risk factors to the recurrence and occurrence of coronary artery disease in the family.
\end{abstract}

Keywords: Coronary artery disease, Prevention and home management, wives of patients with coronary artery disease

\section{Introduction}

Coronary artery disease (CAD) is the most common type of cardiovascular disease and leading cause of death worldwide. It is on the rise and has become a true pandemic across the world ${ }^{1}$. It is a condition where there is narrowing or blockage of the coronary arteries, by the accumulation of fatty streaks, in a way that reduces blood flow to the myocardium, and may result in acute coronary syndrome, and sudden death. CAD has received great attention nowadays, with its grip on mortality and morbidity. The age standardized death rates for CAD are declining in many developed countries but are increasing in developing and transitional countries, partly because of demographic changes, urbanization, and lifestyle changes. Today approximately 3.8 million men and 3.4 million women die each year from CAD 2 . It has reached great proportions striking more and more at younger subjects. According to WHO reports, incoming years it will result in the greatest epidemic mankind has ever faced unless we are able to reverse the trend by concentrated research into its cause and prevention ${ }^{3}$. The modifiable risk factors of CAD include elevated serum lipids, hypertension, tobacco use, physical inactivity, obesity, diabetes mellitus, metabolic syndrome, stress, and high blood homocysteine levels. ${ }^{4}$ This highlights the need for appropriate home management to prevent, modify or retard the progression of the disease. Atherosclerosis is a gradual process, and it starts even early in childhood. It is the role of mother to mold habits of the child. They are the key change agents who can bring about changes in the lifestyle practices to promote a better health 
in the family, and so in society, community and whole nation and whole world. The wives should be made aware of their wrong practices, impacts of the unhealthy practices and how to change their wrong practices. Wives' role in symptom recognition and timely prompt action saves the lives of husbands. Investigator in her clinical experience observed that increased number of patients are admitted with recurrence of symptoms of CAD. Hence the investigator is interested to assess the knowledge and practice of wives of CAD patients regarding prevention and home management of CAD.

\subsection{Problem Statement}

A study to assess the knowledge and practice related to prevention and home management of coronary artery disease, among wives of the patients with coronary artery disease, seeking treatment from Govt. Medical College Hospital, Kozhikode.

\subsection{Objectives}

- Assess the knowledge regarding prevention and home management of coronary artery disease among wives of patients with coronary artery disease.

- Assess the practice of wives of patients with coronary artery disease related to prevention and home management of coronary artery disease in the family.

- Assess the relationship between knowledge and practice among wives of patients with coronary artery disease related to prevention and home management of coronary artery disease.

- $\quad$ Find the association of knowledge and practice related to prevention and home management of coronary artery disease among wives of patients with coronary artery disease with selected variables

\subsection{Operational Definition}

- Coronary artery disease refers to the blockage of one or more arteries that supply blood to the heart and is manifested as angina or myocardial infarction.

- Knowledge related to prevention and management of coronary artery diseases: refers to awareness of the wives of patients with coronary artery disease related to prevention of further attacks and home management of coronary artery disease, which includes dietary modification, need for regular exercise, stress reduction ,importance of avoiding smoking and alcoholism, identification of symptoms and timely management, need for drug compliance and follow up as assessed by Structured interview schedule.

- Practice related to prevention and home management of coronary artery disease: refers to actions performed by the wives of patients with coronary artery to prevent further attacks of angina/myocardial infarction in husband and other members of the family, which includes modification in the diet, ensuring regular exercise and avoidance of smoking and alcoholism, practice of stress reduction measures, identification of symptoms and timely management and ensuring compliance to treatment and follow up ,assessed by Structured interview schedule.

- Patients with coronary artery disease refers to patients with a second or further attack of angina or myocardial infarction and a minimum duration of 6 months after the diagnosis of coronary artery disease.

- Wives of patients with coronary artery disease refers to spouse of the patients with coronary artery disease, whose age is less than or equal to 65 years and who understands Malayalam/English and willing to participate in the study.

- Selected variables: refers to wives' age, education, occupation, duration of coronary artery disease of spouse, type of family, monthly income of family.

\subsection{Assumption}

- Patients with coronary artery disease need lifelong management for the prevention of further attacks and to improve quality of life.

- Wives of patients with coronary artery disease have key role in the family to prevent further attacks of coronary artery disease in spouse and family members

- Adequate knowledge regarding prevention and management of coronary artery disease among wives of patients with coronary artery disease leads to prompt practices in the family to prevent it

\subsection{Hypotheses}

- H1-There is significant relationship between knowledge and practice related to prevention and home management of coronary artery disease.

- H2- There is significant association between knowledge regarding prevention and home management of coronary artery disease with selected variables.

- H3-There is significant association between practice related to prevention and home management of coronary artery disease with selected variables.

\section{Research Methodology}

- Research approach: Non-experimental approach

- Research design: Descriptive survey design

- Setting: Medical and cardiology wards of Govt. Medical College Hospital, Kozhikode

- Population: Wives of patients with coronary artery disease 
- Sample: Wives of patients with coronary artery disease admitted in medical and cardiology wards of Medical College Hospital, Kozhikode.

- Sampling technique: Judgmental sampling

- $\quad$ Sample size:116

\subsection{Tool and Technique}

Tool 1: structured interview schedule for assessing knowledge regarding prevention and home management of

CAD

- $\quad$ Section 1 -Socio personal data of wives of patient with CAD, includes age, religion, education, occupation, type of family and monthly income of the family.

- Section 2-clinical data of patients of with coronary artery disease, which consists of duration of illness, number of hospitalizations related to CAD within 1 year, lipid profile, and unhealthy habits.

- Section 3- structured interview schedule to assess knowledge of wives of patients with coronary artery disease in different domains. The different domains were General aspects of CAD, Diet, Smoking cessation, Stress reduction, Exercise, Sexual life after CAD, Identification of symptoms, Timely management of pain, Drug compliance and follow up.

- Tool 1-Categorization of knowledge of wives with coronary artery disease per score attained:

- 0-30: poor knowledge; 31-60: average knowledge; 61-90: Good knowledge

Tool 2: structured interview schedule for collecting data about practice related to prevention and home management of CAD.

It consists of questions under different domains (A-H) namely Dietary habits, ensuring regular exercise, Avoidance of smoking, Avoidance of alcoholism, Stress reduction practices, Identification of symptoms and timely management, Compliance to medication and follow up.

Tool 2- Categorization of practice of wives with coronary artery disease per score attained: 0-13: poor practice; 14-26: average practice; 27-40: Good practice

\subsection{Data Collection Procedure}

After obtaining permission from Institutional Ethics Committee from KUHS and getting administrative sanction from Medical and Cardiology Department of Govt. Medical College, Kozhikode, the study was conducted from 09/4/2015 to $19 / 5 / 2015$. The Investigator met each sample, introduced herself and established a rapport. The purpose of study was explained, and informed consent was obtained. Each sample was interviewed separately ensuring their comfort and privacy. Investigator collected socio personal data, assessed the knowledge and practice of the housewives regarding prevention and home management of CAD by using structured interview schedule. It took approximately 20 minutes to collect data from each sample. The clinical data of the patient CAD was obtained from case record by obtaining permission from the patient. The study subjects were very cooperative. Responses were marked and data was statistically analyzed.

\subsection{Major Findings}

\subsubsection{Section1 Findings on Sample Characteristics}

This section deals with socio personal data of the samples. It includes age, religion, education, and occupation. This section also deals with the age, duration of illness and unhealthy habits of the patient with CAD. Most of the (36.2\%) participants belong to the age group of 46-55years. More than half of participants (56.9\%) belonged to Hindu religion, most of them (43.1\%) had only primary education and majority of them were housewives (73.3\%). Vast majority belonged to nuclear family. Other findings revealed that 33.3\% of the patients with CAD belonged to age group of 46-55 years of age. Most of $(81.9 \%)$ of patients had duration of illness of more than 1 year. while $41.4 \%$ of them were ex-smokers, $13.8 \%$ had present habit of smoking

\subsubsection{Section IIa}

Knowledge of wives of patients with CAD related to prevention and home management of patients with CAD. The minimum score on knowledge is 0 and maximum score is 90 . The knowledge is graded as poor (0-30), average (31-60) and good (61-90).

\begin{tabular}{|c|c|c|}
\hline $\begin{array}{c}\text { Knowledge Related to Prevention and Home Management } \\
\text { of Patients with CAD }\end{array}$ & $\mathbf{f}$ & $\mathbf{\%}$ \\
\hline Poor & 57 & 49.1 \\
\hline Average & 53 & 45.7 \\
\hline Good & 6 & 5.2 \\
\hline
\end{tabular}

Table 1: Distribution of Participants Based on Knowledge Related to

Prevention and Home Management of Patients with CAD (N=116)

\subsubsection{Section II b}

Knowledge about dietary modifications related to prevention and home management of patients with CAD 
The findings were, $35.4 \%$ of participants had poor knowledge, $47.4 \%$ had average knowledge and only $17.2 \%$ of participants had good knowledge on dietary modifications related to prevention and management of CAD in the family.

\subsubsection{Section II c}

Knowledge about exercises related to prevention and home management of patients with CAD. The minimum score on knowledge about exercises related to prevention and home management of patients with CAD is 0 and maximum score is 14 . The knowledge is graded into poor (0-5), average (6-10) and good (11-14) score

\begin{tabular}{|c|c|c|}
\hline Knowledge about Exercise to Prevent CAD & f & $\mathbf{\%}$ \\
\hline poor & 108 & 93.1 \\
\hline Average & 8 & 6.9 \\
\hline Good & 0 & 0 \\
\hline
\end{tabular}

Table 2: Distribution of Participants Based on Knowledge about Exercises Related to Prevention and Home Management of Patients with $C A D(N=116)$

\subsubsection{Section II d}

Knowledge about sexual life after an attack of CAD related to prevention and home management of patients with CAD

The relevant finding was majority of the participants (96.6\%) had poor knowledge and none had good knowledge about sexual life after $\mathrm{CAD}$

\subsubsection{Section II}

Practice of wives of patients with CAD related to prevention and home management of patients with CAD

\begin{tabular}{|c|c|c|}
\hline $\begin{array}{c}\text { Practice Related to Prevention and Home } \\
\text { Management of Patients with CAD }\end{array}$ & $\mathbf{f}$ & $\mathbf{\%}$ \\
\hline Poor & 48 & 41.4 \\
\hline Average & 68 & 58.6 \\
\hline Good & 0 & 0 \\
\hline
\end{tabular}

Table 3: Distribution of Participants Based on Practice Related to Prevention and Home Management of Patients with CAD (N=116)

\subsubsection{Section IIIa}

Dietary Practice of wives of patients with CAD related to prevention and home management of patients with CAD

More than half of participants (61.2\%) had only average dietary practices in the family and only $1.7 \%$ had good dietary practices. About $37.1 \%$ had poor dietary practices.

\subsubsection{Section III b}

Practice of consumption of fish in the family related to prevention of CAD in the family

\begin{tabular}{|c|c|c|}
\hline Types of Fish Consumed & f & \% \\
\hline All types of fishes & 75 & 64.7 \\
\hline Crabs, mussels, prawn, and fishes & 36 & 31 \\
\hline Not using fishes & 5 & 4.3 \\
\hline
\end{tabular}

Table 4: Distribution of Participants Based on the Consumption of Fish in the Family Related to Prevention of CAD in the Family ( $N=116)$

\subsubsection{Section IIIC}

Practice based on the method of cooking fish in the family related to prevention and home management of patients with CAD

Findings revealed more than half (58.6\%) of participants use oil but no coconut for cooking fish in their family.

\subsubsection{Section IIId}

Practice of consumption of meat in the family related to prevention of CAD in the family

Result depicts almost half (44.8\%) of the participants' family consumed chicken only.

\subsubsection{Section III e}

Practice of the amount of cooking oil used for cooking related to prevention of CAD in the family per person per month 


\begin{tabular}{|c|c|c|}
\hline Amount of Oil Use Per Person Per Month & f & $\mathbf{\%}<$ \\
\hline$<1 / 2 \mathrm{~L}$ & 31 & 26.7 \\
\hline $1 / 2-1 \mathrm{~L}$ & 49 & 42.2 \\
\hline$>1 \mathrm{~L}$ & 32 & 27.7 \\
\hline Don't Know & 4 & 3.4 \\
\hline
\end{tabular}

Table 5: Distribution of Participants Based on the Amount of Cooking Oil Used for

Cooking Related To Prevention of CAD in the Family per Person per Month $(N==116)$

\subsubsection{Section III f}

practice of consumption of dairy products in the family related to prevention of CAD in the family

The findings were, more than half (62.1\%) of participants' family consume milk with fat and (55.2\%) of participants serve whole egg to their husbands.

\subsubsection{Section III g}

Practice of consumption of fruits \& vegetables in the family related to prevention of CAD in the family

Only $42.2 \%$ of the participants family consume fruits and vegetables daily.

\section{$\underline{\text { 2.3.14 Section III } h}$}

Practice based on the practice dining in the family related to prevention of CAD in the family

Less than half (31.9\%) of participants' family have the habit of eating food while watching TV.

\subsubsection{Section III i}

Practice based on practice of exercise in the family related to prevention and home management of patients with

CAD

\begin{tabular}{|c|c|c|}
\hline Practice of Exercise in the Family & f & $\mathbf{\%}$ \\
\hline Poor & 99 & 85.3 \\
\hline Average & 17 & 14.7 \\
\hline Good & 0 & 0 \\
\hline
\end{tabular}

Table 6: Distribution of Participants Based on Practice of Exercise in the Family

Related to Prevention and Home Management of Patients With Cad(N==116)

\subsubsection{Section III j}

Practice based on the number of cigarettes smoked per day in the family related to prevention of CAD in the family

\begin{tabular}{|c|c|c|}
\hline Number of Cigarettes Smoked /Day & f & \% \\
\hline <1Pack & 13 & 11.2 \\
\hline 1Pack & 14 & 3.5 \\
\hline$>1$ Pack & 13 & 11.2 \\
\hline Not smoking & 86 & 74.1 \\
\hline
\end{tabular}

Table 7: Distribution of Participants Based on the Number of Cigarettes Smoked Per Day in the Family Related to Prevention of Cad in the Family $(N=116)$

\subsubsection{Section III k}

Practice based on the amount of alcohol consumed in the family

More than half (66.4\%) of participants' family members were not consuming alcohol.

\subsubsection{Section III I}

The cause of stress in the family related to prevention of CAD in the family

Nearly half of the participants (44\%) have economic stress in the family.

\subsubsection{Section III m}

Practice based on the ways of managing stress in the family related to prevention of CAD in the family

Majority of participants (82.8\%) were practicing methods like listening to music, praying and maintaining good relationships to reduce stress in the family. Only $2.6 \%$ of participants' families were practicing yoga for managing stress

\subsubsection{Section III $\mathrm{n}$}

Practice of timely management of pain related to prevention and home management of patients with CAD More than half (51.7\%) of the participants had poor practice in timely management of pain. 


\subsubsection{Section III o}

Practice of managing chest pain in the family related to prevention of CAD in the family

About $55.2 \%$ of participants give Tab. Sorbitrate when their husbands suffer from chest pain. Nearly quarter $(21.6 \%)$ became panic and equally others $(21.6 \%)$ consulted doctor. A few $(0.8 \%)$ kept Tab Sorbitrate under the tongue and consulted the doctor. Another $0.8 \%$ took rest when they had chest pain

\subsubsection{Section III p}

Practice of carrying Tab. Sorbitrate by husbands for emergency use related to prevention of CAD in the family More than half of (50.9\%) of participants' husbands are not carrying Tab. Sorbitrate for emergency use

\subsubsection{Section III q}

Practice of ensuring compliance to drug of patients with CAD related to prevention of CAD in the family Majority of participants ( $94 \%$ ) ensure compliance to drugs related to prevention of CAD in the family.

\subsubsection{Section IV a}

Correlation between knowledge and practice related to prevention and home management of patients with CAD

\begin{tabular}{|c|c|c|c|c|c|}
\hline Variable & Mean Score & SD & n & Pearson's r & p Value \\
\hline Knowledge & 1.5603 & 0.59 & 116 & .263 & $.004^{* *}$ \\
\hline Practice & 1.5862 & 0.49 & 116 & & \\
\hline
\end{tabular}

Table 8: Correlation between Knowledge and Practice Related to Prevention and Home

Management of Patients with CAD

Correlation ${ }^{* *}$ Significance at 0.01 Level

\subsubsection{Section IV b}

Association between knowledge related to prevention and home management of patients with CAD and selected socio personal variables

\begin{tabular}{|c|c|c|c|}
\hline Selected Variables & $\chi \mathbf{2}$ Value & df & p Value \\
\hline Age & 5.78 & 6 & 0.448 \\
\hline Type of family & 1.89 & 4 & 0.756 \\
\hline Education & 25.28 & 8 & $0.001^{* * *}$ \\
\hline Occupation & 25.28 & 6 & 0.147 \\
\hline Monthly income & 10.39 & 6 & 0.109 \\
\hline $\begin{array}{c}\text { Duration of coronary artery disease of } \\
\text { spouse }\end{array}$ & 3.43 & 2 & 0.180 \\
\hline
\end{tabular}

Table 9: Significance of Association between Knowledge Related to Prevention and Home Management of Patients with CAD and Selected Socio Personal Variables Association ${ }^{* * *}$ Significance at 0.001 Level

\subsubsection{Section IV c}

Association between practice related to prevention and home management of patients with CAD and selected socio personal variables

\begin{tabular}{|c|c|c|c|}
\hline Selected Variables & $\boldsymbol{\chi 2}$ Value & df & p Value \\
\hline Age & 5.62 & 3 & 0.131 \\
\hline Type of family & 1.24 & 2 & 0.537 \\
\hline Education & 4.57 & 4 & 0.334 \\
\hline Occupation & 8.49 & 3 & $0.037^{*}$ \\
\hline Monthly income & 3.77 & 3 & 0.287 \\
\hline $\begin{array}{c}\text { Duration of coronary artery disease } \\
\text { of spouse }\end{array}$ & 1.27 & 1 & 0.258 \\
\hline
\end{tabular}

Table10: Significance of Association between Practices Related to Prevention and Home Management of Patients with CAD and Selected Socio Personal Variables Association *Significance at 0.05 Level

\section{Discussion}

The present study revealed that among the wives of patients with CAD, almost half of them (49.1\%) had poor knowledge and only 5.2\% had good knowledge related to prevention and home management of CAD. Other highlights of the result were, nearly half of participants $(41.4 \%)$ had poor practices and more than half $(58.6 \%)$ of wives had only average practices and none had good practice to prevent and manage CAD in the family. Researcher strongly supports the statement in an article, that in case of a heart attack, it has been seen that the lack of knowledge often causes a delay in handling the situation, which could aggravate the damage and, in some cases, prove to be fatal. And with the changing 
lifestyle practice, both men and women share the same risk. ${ }^{5}$. This projects the importance for the need for assessing the knowledge and practice of wives of patients with CAD. The present study revealed that 34.5\% of the patients with CAD belonged to the age group of 46-55 years. This shows the presence of coronary artery disease in younger ages. This finding has a close relation to the finding of Indian heart association ${ }^{5}$

The present study reveals that $35.3 \%$ of participants had poor dietary practices and $47.4 \%$ had average level of practice and only $17.2 \%$ had good dietary practices to prevent and manage CAD. It is seen that $31 \%$ of participants' family members were consuming crabs, mussels and prawns which are high in cholesterol, along with other fishes.42.2\% used $1 / 2$-1Lof oil per person per month while the required amount is $<1 / 2 \mathrm{~L}$ per person per month, which indicates increased fat intake by the family members of the participants. $62.1 \%$ of participants' family members were consuming milk with fat and $55.2 \%$ of participants included whole eggs in the diet of their husbands. These results are consistent with a crosssectional study done among patients with established CAD 6 .Majority of the participants (93.1\%) had poor knowledge and $85.3 \%$ had poor practice of exercise and none had good knowledge or practice of exercise. This shows presence of a major risk factor in the family. A comparative study in Japan ${ }^{8}$ revealed that mortality was lower in patients who underwent an exercise or diet intervention than in patients who did not. Nearly half of the participants' family (44\%) had to deal with stress mainly due to economic constraints. Literature suggest that having a group of personality characteristics including time urgency, competitiveness, hostility, and impatience is linked to an increased risk of coronary disease. ${ }^{7}$ More studies can be done by including psychosocial factors like hostility, anxiety, type A behavior pattern etc. to find the relation between stress and CAD. The researcher could not reach a consensus on the effect of Smoking on CAD. More studies need to be done to reach a conclusion.

\section{Conclusion}

The study findings reveal the fact that risk factors for development of coronary artery disease are persisting in the family and so individualized cardiac counselling of the wives are very essential to protect themselves, their children and other family members from the risk of developing coronary artery disease.

\section{Limitations}

Generalizability is limited because of small sample size.

\section{Recommendations}

- The study can be replicated on a larger sample in different settings

- The study can be done by including all members in the family.

- Study can be conducted to evaluate the role of psychological factors in the etiology and prognosis of coronary artery disease.

- A follow up study can be done to determine the long-term result of cardiac counseling in housewives regarding prevention and home management of CAD.

\section{References}

i. Definition of Coronary artery disease, accessed through internet, http: //www. medicine net .com

ii. Report from WHO Web site. Accessed through internethttp://www WHO.int

iii. The prevention and control of major cardiovascular diseases: report on a conference, World Health Organization Regional office for Europe. Accessed through www.medicographia.com

iv. Linda MC, Bucher l, Nursing management coronary artery disease and acute coronary syndrome, Lewis, Heitkemper Dirksen, O’Brien Text book of Medical surgical nursing,7thedition;2009:page no:787.

v. Krishnan MN, Coronary artery disease and risk factors in India. Indian heart journal.2012, july:64(4):364-367

vi. Cyril J, Risk factors for coronary artery diseases: A study among patients with ischemic heart disease in Kerala; Heart India 2013;1:7-11

vii. Langabeer JR, Economic methods in the century trial--a comprehensive lifestyle modification study for managing coronary artery disease, June 1, 2012; 5 (3); 333-6 accessed through Medline

viii. Suzuki T, Kohro T, Hayashi D, Yamazaki T, Nagai R, Frequency, and impact of lifestyle modification in patients with coronary artery disease: the Japanese Coronary Artery Disease (JCAD) study. American. Heart Journal. February 1, 2012; 163 (2); 268-73 